\title{
Rehabilitation of industrial areas for social needs of society through the creation of children's technoparks \\ Baltina A. ${ }^{1}$, Krasavina N. ${ }^{2}$, Larionova . $^{3}$ \\ Реабилитация промышленных территорий под социальные нужды общества на примере создания детских технопарков Балтина А. С. ${ }^{1}$, Красавина Н. Ю. ${ }^{2}$, Ларионова В. А. ${ }^{3}$
}

\author{
${ }^{1}$ Балтина Анна Сергеевна / Baltina Anпа-магистрант; \\ ${ }^{2}$ Красавина Надежда Юрьевна / Krasavina Nadezhda - магистрант;

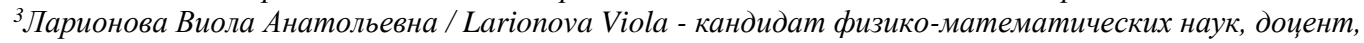 \\ кафедра экономики и управления строительством и рынком недвижимости, \\ Высшая школа экономики и менеджмента, \\ Уральский федеральный университет им. первого Президента России Б. Н. Ельиина, г. Екатеринбур
}

\begin{abstract}
Аннотация: в статье анализируются проблемы развития дополнительного инженерного образования 6 России и проблемы реабилитации промыциленных территорий. В статье рассмотрена российская система образования, которая подвергается серьезной перестройке под воздействием запросов общества и происходящей в стране перестройки идеологии, экономики и психологии мышления. Вместо экономического образования становятся популярными технические направления, но лишь 5\% школьников занимаются научно-техническим творчеством. В статье анализируется зарубежный и отечественный опыт, который позволяет понять, что создание технопарков - это один из вариантов решения указанных проблем.

Abstract: the article analyzes the problems of the development of supplementary engineering education in Russia and the problems of rehabilitation of industrial areas. The article considered Russian education system, which is subject to major restructuring under the demands of society and under the ongoing change of the country's ideology, economics and psychology of thinking. Instead of economical field of education is becoming popular technical fields, but only 5\% of students involved in sci-tech creativity. The article analyze the foreign and domestic experience, which allows us to realize, that the creation of technoparks is one of the way of solving these problems.
\end{abstract}

Ключевые слова: дополнительное образование, инженерное образование, промышленная территория, технопарк.

Keywords: supplementary education, engineering education, industrial area, technopark.

В России на сегодняшний день наблюдается неравномерность пространственного экономического развития страны. Сформировавшаяся система расселения на муниципальном уровне состоит из доминирования крупных городов-мегаполисов, которые стягивают большую часть трудовых ресурсов, капитала и инвестиций. В стране отсутствуют высокоэффективные промышленные кластеры, а существующая инфраструктура требует модернизации и диверсификации. В свою очередь, взаимодействие между регионами России малопродуктивно, а мобильность населения сильно затруднена, в связи с большим территориальным пространством страны. В основном, для решения этих проблем нужно разрабатывать и реализовывать комплексную стратегию, которая направлена на гармоничное развитие территорий [2].

Наиболее актуальные проблемы развития территории города, в связи с вышеизложенным, заключены в сфере комплексного преобразования городского пространства, его экологизации и эстетизации, а также в том, что стратегическое развитие городских агломераций должно реализовываться в одном направлении. В общем виде это все представляет собой процесс реабилитации городского пространства.

По мере переноса промышленных предприятий за границы городов встает вопрос о путях изменения состояния нарушенных территорий. Промышленная территория не сходна природному ландшафту, поэтому она содержит определенный ресурс, делающий возможным изменение ее эстетикофункциональных характеристик. Будучи заброшенной, данная территория становится фактором риска, она снижает качество городской среды и негативно влияет на уровень жизни населения. Следует еще отметить и то, что экономический потенциал этих пространств очень высок, поэтому целесообразно приспособлять данные территории под нужды общества. Одним из возможных вариантов их приспособления может стать приспособление данных площадей под детские технопарки [1].

Исследуя зарубежный опыт довузовского инженерного образования, можно сделать вывод о том, что Америка уделяет большее внимание развитию детей в данной области, чем другие страны мира. Самый большой процент детей занимающихся в научно-технологических центрах и технопарках, отмечается в США - 20\%, после него у Европы - 10\% и у Японии - 8\%. В США существует две крупные организации, 
которые специализируются в данной области: "American Society for Engineering Education" и "Engineering For Kids".

B "American Society for Engineering Education" довузовское образование идет через проект «Science and Engineering Apprenticeship Program», который направлен на подготовку детей старших классов. Данная программа предоставляет возможность ученикам старших классов принимать участие в научной и исследовательской деятельности в университетских лабораториях в период летних каникул. Ее основная цель- поддержка и развитие школьников, заинтересованных в научной и инженерной областях, путем обучения и помощи в проведении исследований [3].

В свою очередь, "Engineering For Kids" направлен на подготовку детей от 4 до 14 лет. Основная цель данной программы заключается в обучении науке, технологиям, инженерным специальностям и математике в веселой и разнообразной форме. Она реализуется в виде игр, занятий в группе, выездных лагерей и клубов. По данным на 2016 год у них функционируют 145 центров в Северной и Южной Америке, в Африке, Европе и Азии. Из них 119 центров находятся в Северной Америке. В России нет ни одного центра "Engineering For Kids" [4].

Рассматривая российскую систему образования, можно сделать вывод о том, что она подвергается серьезной перестройке под воздействием запросов общества и происходящей в стране перестройки идеологии, экономики и психологии мышления. При этом предпринимаются попытки перечеркнуть все, что было достигнуто прежде, а существовавшая система образования подвергается серьезной критике.

Для того чтобы дети были всесторонне развиты и готовы к взрослой жизни существует множество различных систем дополнительного образования. Но, к сожалению, сегодняшняя система данного образования не является инструментом подготовки детей и подростков к участию в будущем технологическом прорыве. Глобальный технологический прогресс предъявляет серьезные вызовы, в том числе в сфере детского досуга. Между тем лишь не более 5\% школьников занимаются научнотехническим творчеством.

Рассматривая отечественный опыт довузовского инженерного образования, стоит отметить, что только с 2010 года в России начинают постепенно открываться инженерные классы в школах и дополнительные образовательные площадки. В 2011 году с целью развития системы дополнительного образования детей в Свердловской области была создана Некоммерческая организация «Ассоциация учреждений дополнительного образования детей Свердловской области» [7]. В данный момент у них существует проект «Детская инженерная школа», который находится на этапе реализации выездных школы. Во время нее дети принимают участие не только в летней оздоровительной кампании, но и заниматься с привлеченными специалистами и работают над своими проектами. Также, хотелось бы отметить и то, что помимо указанной выше инженерной школы, на территории Свердловской области существуют различные детские технические школы, в частности УрФУ поддерживает некоторые из них, например, детская технологическая школа «Легокомп». «Легокомп» - это современная детская технологическая школа, которая работает в четырех отделениях, направленных на формирование технологической грамотности в области высоких технологий, подготовку в области программирования и робототехники.

В 2015 году появился проект создания технопарков, разработанный правительственным Агентством стратегических инициатив - «Национальная система мотивации детей к всестороннему развитию». Цель проекта - вовлечение как можно большего количества учащихся в инженерно-конструкторскую и исследовательскую деятельности в различных областях науки. Всего девять направлений нейротнология и нейробиология, микробиология и биотехнология, прикладная космонавтика, перспективные транспортные средства, малая беспилотная авиация, маломерное инновационное судостроение, мехатроника и прикладное программирование, геоинформатика, программирование и защита информации. В технопарках могут заниматься дети от 5 до 18 лет совершенно бесплатно и они оснащены всем необходимым оборудованием [5].

Первый в России детский технопарк «Кванторум Югры» открылся 28 ноября 2015 года в городе Ханты-Мансийск на базе «Технопарка высоких технологий». В «Кванториуме» дети в игровой форме осваивают самые передовые технологии, получают практические навыки их применения. Они имеют возможность заниматься в оснащенных всем необходимым лабораториях и при этом у них есть возможность переходить из одного направление в другое. За 2016 год данный проект уже реализуется в 15 регионах России, что значительно увеличивает доступность дополнительного инженерного образования для населения страны [6].

Однако проблема отсутствия подходящих площадок для развития дополнительного инженерного образования и его финансирования остается актуальной по сей день. Это происходит из-за того, что требуется специализированное оборудование для обучения по техническим направлениям, под которое нужно либо большое пространство в здании, либо специализированное помещение, которые трудно найти. 
Исходя из вышеизложенного, можно сделать вывод о том, что промышленные территории содержат в себе уникальный потенциал. Их приспособление под детские технопарки позволит реализовать несколько важных аспектов: социальную функцию, образовательную и организационную составляющие. Данные территории хорошо подходят для создания центров, которые нуждаются в использовании специализированного оборудования и которые будут способствовать повышению качество жизни населения. Следует также отметить и существующие риски, связанные с промышленными территориями, которые нужно учитывать при их реабилитации. Самыми главными из них являются риски экологической опасности и аварийности таких территорий.

Создания детских технопарков, учитывая существующие риски, позволит не только повысить уровень образования населения в инженерных областях, но и рационально приспособить специализированные территории, которые снижают качество городской среды и негативно влияют на уровень жизни населения.

\section{Лumepamypa}

1. Быстрова Т. Ю. Реабилитация промышленных территорий городов: теоретические предпосылки, проектные направления. Часть 1. Академический вестник УралНИИпроект РАACH, 2013 г.

2. Демидова E. В. Реабилитация промышленных территорий как части городского пространства, Академический вестник УралНИИпроект РААСН, 2013 г.

3. American Society for Engineering Education. [Электронный ресурс]: Американское сообщество инженерного образования. Режим доступа: https://www.asee.org/ (дата обращения: 12.10.2016).

4. Engineering For Kids. [Электронный pecypc]: Инженерия для детей. Режим доступа: http://engineeringforkids.com/ (дата обращения: 12.10.2016).

5. Агентство стратегических инициатив. Новая модель системы дополнительного образования детей. [Электронный ресурс]. Режим доступа: https://asi.ru/social/education/ (дата обращения: 30.10.2016).

6. Кванторум ЮГРЫ. Технопарк высоких технологий. [Электронный ресурс]. Режим доступа: http://www.kvantorium86.ru/about/\#kvantorium/ (дата обращения: 30.10.2016).

7. НКО Ассоциация учреждений дополнительного образования детей Свердловской области. [Электронный ресурс]. Режим доступа: http://udo.irc66.ru/ (дата обращения: 15.11.2016). 